\title{
The Sketch Teaching of Basic Training of Chinese Painting Modeling in University
}

\author{
Xiaojuan Wang \\ Heihe University \\ Heihe, China
}

\begin{abstract}
In recent 50 years, the sketch basic course of Chinese painting specialty in university doesn't fully analyze the characteristic of Chinese painting specialty itself. The sketch basic course is severely disjointed with professional main course and makes many detours in teaching. This article points out the problems and reasons existing in sketch basic course of Chinese painting specialty in university, aims at the professional characteristic of Chinese painting itself, starts from analyzing the basic elements of fine art works, puts sketch basic course into the whole teaching of Chinese painting specialty to grasp and preliminarily draw the conclusion: the most superposition between sketch basic course of Chinese painting specialty and professional main course is the beauty of form of works. So in sketch basic course, we should take the training for students' understanding and practical ability for "aesthetic feeling of form" as the core goal of teaching.
\end{abstract}

Keywords-sketch teaching; Chinese painting specialty; aesthetic feeling of form; reform

\section{INTRODUCTION}

"Sketch is the basis of all modeling art". Indeed, sketch uses more economic investment to intensively and efficiently train students' observation, analysis, judgment and basic performance ability. All fine art institutes regard sketch course as the primary basic course and establish it in modeling art specialty. Now the sketch teaching applied by us is the teaching practice product of basic education of western academic modeling art in recent 400 years, mainly aims at the modeling art subject with western tradition such as oil painting, sculpture and printmaking. (Because it produces and develops in the west, the Chinese painting specialty is not involved from beginning to end.) In recent 100 years, the introduction and absorption of the fine arts education circle in our country for western sketch teaching system are mainly professional services of oil painting, sculpture and printmaking and the consideration for Chinese painting specialty is very less. In the first 50 years when we introduce western sketch teaching system (give priority to the European style sketch teaching system introduced from Europe by $\mathrm{Mr}$. Xu Beihong, etc), Chinese painting specialty holds a "resistant" attitude towards sketch teaching and facts prove that western sketch teaching doesn't have fundamental influence on the development of Chinese painting in this period. After the founding of the nation, influenced by the overall impact of "great unification" from the sketch teaching system of Cischakov from the Soviet Union, it passively accepts western sketch teaching. The passive acceptance continues until the end of the 20th century. During this period, the influence of sketch teaching has on Chinese painting specialty teaching is half good and half bad. The western sketch teaching system itself should be blamed, because this system is not to serve the teaching of Chinese painting specialty. Because there isn't a whole set of scientific, systematic, complete and pointed "sketch basic course teaching mode and method with the characteristics of Chinese painting specialty" which uses supporting the development of Chinese painting specialty as the core (other basic course such as coloring course also has similar abovementioned problem, but it is not in the scope of this article). So establishing an above-mentioned teaching mode becomes the most pressing problem in front of researchers of Chinese painting basic teaching.

\section{The BeAUty OF Form IN CHINESE PAINTING}

Chinese painting emphasizes "image", "artistic conception", "gathering the thoughts", "straight to the nature of mind" and the integral observation and grasp of cosmos and life and doesn't confine to specific object and the choice of object. So in basic course (including sketch and color, etc.), we shouldn't walk this way of "starting from the description of special object and then master the law of art". While traditional western sketch teaching mode is teaching system and mode of this kind. The western sketch teaching mode carries through the sketch practice of geometric solid, still life, gypsum head portrait, human head, gypsum bust, character bust, gypsum full-length portrait, character fulllength portrait, human body and then assembling human body of the figure according to the order. The purpose is to practice to master the methods of rational analysis through the description and sketch of specific objects. The theoretical basis (direct power) is natural science or science of thinking such as composition, anatomy, optics, mechanics, chromatics, perspective science and psychology, etc. In the process of emphasizing reason and rational analysis, the subtle influence of selected specific teaching aids (the typical images such as David, Mose, Voltaire, La Marseillaise with symbol properties of characteristic in western figurative modeling art) in several hundred years makes students form the figurative thinking mode of "object" first to shape a particular image as the center. From the level of three elements of fine art works (aesthetic feeling of form, content and implication), this is "content is the core" namely "what 
to draw" is the most important. Although in creation stage, the three elements appear as an integration in every work, the students under western sketch teaching system consider "what to draw" first in creation stage, which conforms to the situation that western traditional modeling art belongs to system of representational modeling.

For Chinese painting specialty, "what to draw" is not important, and what counts is "how to draw". This situation is determined by the artistic characteristics and ideological implication of Chinese painting. Since the content selection and the research with the content itself as the core not should be emphasize to master in the basic course stage of Chinese painting specialty, and internal implication (content) is recognized that it is not be solved mainly depending on classroom teaching, then the teaching and research emphasis of sketch basic course of Chinese painting specialty naturally lie in the "aesthetic feeling of form" in three elements of fine art works except for content and implication.

Aesthetic feeling of form is a relatively abstract, relatively independent part which can be analyzed rationally and quantized specifically. In addition, it is the master key (while what it can "open" is only the "form" part of fine art works) recognized by eastern and western artistic circle which can open all the fine art works. For the specialty of Chinese painting which attaches importance to "form", starting from "form" to learn on the contrary can more reduce the disturbance for students who have little rational knowledge and practical experience. Chinese painting has a lot of "irrational" components and we must depend on "apperception" to analyze and grasp. While "apperception" itself is zen language and itself has blurry and unknown components. "Beauty of form" itself, relative constancy and chronotaxy are exactly suitable for beginners

\section{HOW TO CONVEY THE Formal BEAUTY OF CHINESE PAINTING THROUGH SKETCH}

In consideration of the characteristics of Chinese painting attaching importance to "artistic conception" and skill in the aspect of aesthetic feeling of form, it is more reasonable to divide aesthetic feeling of form into three parts of composition, modeling and pen and ink. As the symbolic characteristic of Chinese painting, pen and ink has become the center of the research of form aesthetic feeling research. Composition is the first pass of successful work and also the first step to grasp form aesthetic feeling. Modeling is the part most difficult to describe in form aesthetic feeling, because itself has the character of content and implication to a great extent. But before student admission, there are certain realistic techniques (the understanding of representational modeling), so it is not too laborious to understand the modeling, besides, as it turns out, what students most get used to and be good at is to understand form aesthetic feeling starting from modeling.

\section{A. Composition}

Composition refers to the process that organizes and arranges different parts of the object to be expressed and forms a coordinating and complete picture according to the requirements of painting theme and main idea. It is also called "art of composition", "overall arrangement" in Chinese painting. The composition can be understood from the following five aspects and the embodiment in the picture should pay attention to achieving mastery through a comprehensive study of the subject.

1) Contour line. It can confirm the basic proportion of positive and negative space in the picture and also can decide part of the "dynamic tendency" in the picture. The positive and negative is relative and they cannot be simply understood as main content and background.

2) Structure line. It consists of the basic structure of an object and then becomes the constituent part of "dynamic tendency" (artistic conception) in the picture. The main structure line of object often becomes the main part of "dynamic tendency" in the picture.

3) Center of gravity line. Vertical to the ground through the inner center of gravity of object volume and the direction is often downward. The grasp of the center of gravity line is relative objective, which can refer to physics relevant to the knowledge of the center of gravity of object.

4) Dynamic line. The integral "dynamic tendency" of the picture through selectively synthesizing and recombining the contour line, structure line, center of gravity line. The dynamic line has the main part and the secondary part. The direction of the secondary part is likely to conflict with the direction of the main part, which exactly embodies the richness of dynamic line.

5) Light shadow line. Decided by the location and intensity of light source, always "no ample scope for abilities" in traditional Chinese painting, shows light shadow and the change of light and shadow. Influenced by "western learning introduced into China" of hundreds of years, more and more countrymen begin to love the Chinese painting expressing light shadow.

\section{B. Modeling}

"Modeling" is the specific cultural behavior of human. From the birth of human, there is modeling activity. All the artistic works and daily products created and made for promoting human civilization and human happiness belong to the modeling activity of human, such as building, articles of daily use and artistic works, etc. In modeling area, modeling can be divided into two categories of artistic modeling and practical modeling. The former generates for meeting human spiritual needs; the latter generates for meet human material needs of life. With the development of human society, the boundary of artistic modeling and practical modeling will be vaguer and their relationships will be closer. Modeling mainly has the following four kinds, which cannot be lumped together and distributed equally in teaching, should be operate according to the following requirements:

1) Concretization modeling. The objective structure of object itself as the research center, conduct relative faithful portrait, mainly aims at beginners. Usually mature Chinese painters start from concretization modeling and properly 
absorb abstract modeling constantly and finally it appears in the feature of image modeling.

2) Image modeling. Start from the author's character personality, and give consideration to author's instant mood according to the need of picture theme, change the objective image of the object. Part of the objective factors of object needs to make corrections and deletions. In creation stage, this modeling style should be the main part. So at the present stage, we should read and appreciate more about this kind of work. The success of image modeling often bases on concretization modeling, but concretization modeling is unequal to all-factor modeling.

3) Abstract modeling. Directly express abstract aesthetic feeling of form itself as the core aim, and make a lot of corrections and deletions for the objective factors of the object itself. This modeling style doesn't conform to Chinese traditional aesthetic habits. While the present Chinese painting works of this kind locates in the period of "clinical test", so we don't advocate beginners to regard it as the main training content.

4) Object modeling. The modeling of works is often defined beyond the painting art category because it goes beyond the planar space. So beginners had better "keep but do not discuss it" at this stage.

\section{Pen and Ink}

In the discussion on traditional Chinese painting, most of the exposition of pen and ink is figurative words, which is not beneficial for class presentation and rational thinking. We should analyze and practice according to the following seven aspects.

1) Sense of potency. Mainly decide through the form of symbol of the language itself and dealing with the strokes. Visual effect: strong or weak (this is the determinant of visual impact)

2) Blur and clear feeling. Determined by the collocation and combination of language sign and the disposition of the form of language sign itself. Visual effect: big or small; dry or wet; thick or thin (the form of sign itself); scanty or dense (the combination between symbols)

3) Weight sense. Determined by the shape and size of language sign itself, combining "sense of potency" to experience. Visual effect: heavy or light

4) Qualitative feeling. Determined by roughness of the outer contour of language sign and textural effect after combination of language signs. Visual effect: rough or smooth

5) Sense of direction. Determined by the composition of line (1-4) (also can set the direction subjectively, not suitable for beginners). Visual effect: specific azimuth pointing of up, down, left, right

6) Sense of speed. Determined by the process of making language symbols, emphasizes timeliness. Calligraphy basis is the core power and determinant. Visual effect: fast or slow
7) Sense of color. The author's character personality as the core, determined by author's artistic accomplishment of color. Instant mood will play some roles. Visual effect: "following your heart".

\section{CONCLUSION}

Finally, the issue concerning us and the most worth our attention is a comprehensive and correct understanding of development direction of computer graphic design. Based on development direction of computer graphic design, while improving the level of computer graphic aided teaching, we must start to develop and study the value of computer graphic design, broaden overall view of design education direction and fill in our blanks in major setup so as to contribute to overall improvement of Chinese computer technology in graphic design teaching and let our modern art design play a more important role in promoting our economic and cultural development.

\section{REFERENCES}

[1] Guo Jing, Model of Talent Cultivation for Higher Vocational Education. Higher Education Press, 2000

[2] Tan Haoqiang, To Meet Third Climax in Computer Polarization. Tsinghua University Press, 2000

[3] Liu Hao, Prospects of Application of Computer Aided Design Technology in Landscape Design. Science Mosaic, 2005.8

[4] Yu Pengfei, Du Yishu, Analysis on Relationship between Computer Aided Design and Hand Painting in Art Design. The Science Education Article Collect, 2008.6

[5] Zhao Ming, Yang Mo, Esthetics Investigation of Computer Aided Design Teaching. Forum on Contemporary Education (Teaching Research), 2011.6

[6] Zhou Yi, Zhou Wei, Investigation of Teaching Method of Computer Aided Design Course. Economy Business, 2014 